\title{
Evolução clínica e avaliação de parâmetros leucocitários e de proteínas de fase aguda na pododermatite infecciosa ovina ${ }^{1}$
}

\begin{abstract}
Vitor S. Carvalho ${ }^{2 *}$, Byanca R. Araújo ${ }^{3}$, Ticianna C. Vasconcelos ${ }^{3}$, Cláudio Chiminazzo 4 , Antonio O. Costa Neto ${ }^{5}$, Maria C.C. Ayres ${ }^{2}$, José E. Guimarães ${ }^{2}$ e Joselito N. Costa ${ }^{6}$

ABSTRACT.- Carvalho V.S., Araújo B.R., Vasconcelos T.C., Chiminazzo C., Costa Neto A.O., Ayres M.C.C., Guimarães J.E. \& Costa J.N. 2012. [Clinical evolution and evaluation of leukocyte parameters and acute phase protein of ovine footrot.] Evolução clínica e avaliação de parâmetros leucocitários e de proteínas de fase aguda na pododermatite infecciosa ovina. Pesquisa Veterinária Brasileira 32(12):1289-1296. Departamento de Patologia e Clínicas, Hospital de Medicina Veterinária, Universidade Federal da Bahia, Rua Ademar de Barros 500, Ondina, Salvador, BA 40170-110, Brazil. E-mail: vitornet@gmail.com

In this paper, Santa Inês crossbred sheep with footrot were evaluated, checking the changes on leukogram and the acute phase proteins. In the first experiment, 70 females were divided into three groups according to their podal scores: a control group (G1) with score 0 , scald group (G2) with score 1 or 2 and a footrot group (G3) with score 3, 4 or 5. During two months, the clinical course and its effect on leukogram were observed at five moments: M1 (day 0), M2 (day 15), M3 (day 30), M4 (day 45) and M5 (day 60). The intensity of the white blood cell count was low magnitude, observing significant changes $(p<0.05)$ as a mild leukocytosis (G3, M4), attributed to neutrophilia and a slight increase in the total number of monocytes (G3, M2 and M3) despite the extensive damage and tissue necrosis existed during the final stage of the disease. In the second experiment, 105 animals from seven farms were used with the objective of isolating the causative agent and to evaluate the effect of disease on total plasma protein and acute phase proteins. The animals were also divided into three groups: control, scald and footrot. In all farms, the isolation of Dichelobacter nodosus was regarded. For the different stages of the disease on the proteins studied there was no significant correlation $(\mathrm{p}<0.05)$ but the haptoglobin in scald and footrot groups showed higher average than the control group. Based on these results, we conclude that the acute phase proteins studied were not efficient in the characterization of the phases of the disease and the leukocyte response was mild, making it difficult to use for this purpose.
\end{abstract}

INDEX TERMS: Footrot, pododermatitis, Dichelobacter nodosus, leukogram, haptoglobin, sheep.

${ }^{1}$ Recebido em 12 de julho de 2012.

Aceito ara publicação em 15 de outubro de 2012.

${ }^{2}$ Departamento de Patologia e Clínicas, Hospital de Medicina Veterinária, Universidade Federal da Bahia (UFBA), Rua Ademar de Barros 5000, Ondina, Salvador, BA 40170-110, Brasil. *Autor para correspondência: vitornet@gmail.com

${ }^{3}$ Programa de Pós-Graduação, Escola de Medicina Veterinária e Zootecnia, UFBA, Salvador, BA.

${ }^{4}$ HIPRA Química e Biotecnologia Ltda, Estrada do Lami 6133, Belém Novo, Porto Alegre, RS 91780-120.

${ }^{5}$ Departamento de Biologia, Escola de Ciências Biológicas, Universidade Estadual de Feira de Santana, Av. Transnordestina s/n, Novo Horizonte, Feira de Santana, BA 44036-900, Brasil.

${ }^{6}$ Centro de Ciências Agrárias, Ambientais e Biológicas, Universidade Federal do Recôncavo da Bahia (UFRB), Campus Universitário de Cruz das Almas, Rua Rui Barbosa 710, Centro, Cruz das Almas, BA 44380-000, Brasil.
RESUMO.- Neste artigo realizou-se a avaliação de ovinos mestiços Santa Inês com pododermatite infecciosa, verificando as alterações no leucograma e proteínas de fase aguda. No primeiro experimento, 70 fêmeas foram separadas em três grupos de acordo com o seu escore podal: Grupo controle (G1) com escore 0; Dermatite interdigital (G2) com escore 1 ou 2 e Pododermatite necrosante (G3) com escore 3, 4 ou 5. Durante dois meses observou-se a evolução clínica e efeitos no leucograma em cinco momentos: M1 (dia 0), M2 (dia 15), M3 (dia 30), M4 (dia 45) e M5 (dia 60). A intensidade do resultado do leucograma foi de baixa magnitude, observando-se alterações significativas $(\mathrm{p}<0,05)$ como uma leve leucocitose (G3, M4), atribuída a neutrofilia e um discreto aumento no número total de monócitos (G3, M2 e M3) apesar do extenso dano e necrose 
tecidual existentes na última fase da doença. No segundo experimento, utilizaram-se 105 animais de sete propriedades com objetivo de isolar o agente etiológico e avaliar os efeitos da doença sobre proteína plasmática total e proteínas de fase aguda. Os animais também foram separados em três grupos: controle, dermatite interdigital e pododermatite necrosante. Em todas as propriedades foi realizado o isolamento de Dichelobacter nodosus. Não houve correlação significativa $(\mathrm{p}<0,05)$ das diferentes fases da doença sobre as proteínas estudadas, porém a haptoglobina dos grupos com animais doentes apresentou médias superiores ao grupo controle. De acordo com a metodologia utilizada e resultados obtidos, conclui-se que as proteínas de fase aguda estudadas não foram eficientes na caracterização das fases da pododermatite infecciosa ovina e que a resposta leucocitária foi branda, tornando difícil sua utilização para este fim.

TERMOS DE INDEXAÇÃO: Pododermatite, Dichelobacter nodosus, leucograma, haptoglobina, ovinos.

\section{INTRODUÇÃO}

A pododermatite infecciosa ovina é uma enfermidade causada pela associação de duas bactérias anaeróbicas: $F u$ sobacterium necrophorum e Dichelobacter nodosus, sendo esta última responsável pela transmissão. A infecção é limitada ao tecido epidérmico do espaço interdigital na pele e no casco (Bonino et al. 2000). No Brasil, a doença que causa redução no ganho de peso e índices reprodutivos tem sido observada em vários estados (Rodrigues et al. 2001, Aguiar et al. 2007, Aguiar et al. 2009).

O diagnóstico clínico é realizado pela observação das lesões, aparecimento de surtos em épocas úmidas e quentes e pelo caráter crônico e recidivante da doença (Whittier \& Umberger 2009). Vários sistemas de escore foram desenvolvidos para auxiliar programas de controle da doença e podem ser utilizados para categorizar a severidade da doença em um rebanho. A avaliação clínica individual das lesões e a sua graduação em escores variam conforme os pesquisadores (Jelinek et al. 2000, Tadich \& Hernandez 2000, Morcombe 2008). Dentre os sistemas, o escore modificado de Egerton é um dos mais utilizados para descrever os vários estágios da pododermatite infecciosa (Bendigo 2007).

Uma possibilidade de avaliar as enfermidades dos animais domésticos é por meio de exames laboratoriais e a determinação da concentração de proteínas de fase aguda vem sendo utilizada (Murata et al. 2004). Contudo, em ovinos, as pesquisas de resposta protéica de fase aguda ainda estão sendo difundidas, apesar de ser, como nas outras espécies, a principal resposta para infecções e danos teciduais, sendo também potencialmente útil para o diagnóstico e prognóstico de doenças (Pfeffer et al. 1993, Skinner \& Roberts 1994). 0 objetivo deste trabalho foi acompanhar a evolução clínica da pododermatite infecciosa ovina, por meio da avaliação do leucograma e concentrações da proteína plasmática total e proteínas de fase aguda durante as diferentes fases da doença, identificando em sua evolução $o$ agente etiológico envolvido.

\section{MATERIAL E MÉTODOS}

A primeira parte do experimento foi conduzida na fazenda experimental da Escola de Medicina Veterinária e Zootecnia da Universidade Federal da Bahia situada na microrregião do Litoral Norte da Bahia com tipo climático variando de úmido a subúmido. Foram utilizadas 70 fêmeas ovinas mestiças da raça Santa Inês, submetidas às mesmas condições sanitárias e nutricionais. Os cascos fo-

\section{ESCORE DESCRIÇÃO}

Dermatite Necrose

0 - Casco sem lesões

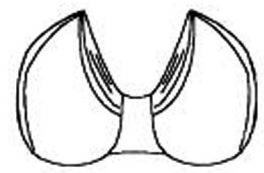

1 - Dermatite Interdigital moderada

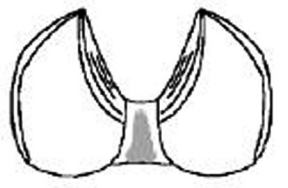

2 - Dermatite Interdigital severa

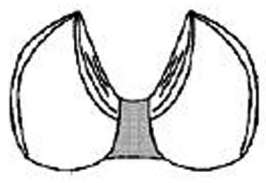

3 - Dermatite interdigital severa e início de necrose na região do talão e sola (axial)

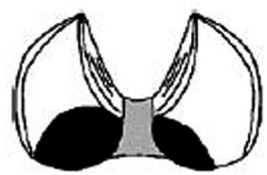

4 - Dermatite interdigital severa com necrose se estendendo por toda a sola até a muralha

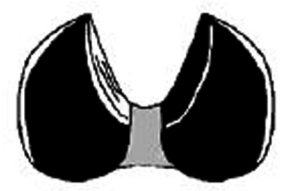

5 - Severa necrose por dentro e fora do casco, se estendendo por toda a muralha

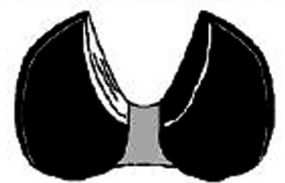

Fig.1. Sistema de escore utilizado para caracterização clínica. Fonte: Bendigo (2007). 
ram examinados quinzenalmente, totalizando cinco observações, a fim de caracterizar o aparecimento das lesões utilizando o sistema de escore modificado de Egerton, onde foi estabelecido um escore de zero a cinco (Bendigo 2007) (Fig.1). As fêmeas foram separadas em três grupos de acordo com o grau de lesão podal: Grupo controle, animais sem sinais clínicos de pododermatite (escore 0); Grupo dermatite interdigital, animais com dermatite interdigital leve a moderada (escore 1 ou 2); Grupo pododermatite necrosante, animais com dermatite interdigital severa e pododermatite necrosante (escore 3, 4 ou 5). Os grupos experimentais permaneceram em contato entre si e a manutenção da condição de saúde dos animais do grupo controle foi realizada com pedilúvios preventivos de formalina $10 \%$. As coletas de sangue para as determinações laboratoriais foram realizadas quinzenalmente, a partir da primeira observação clínica, totalizando cinco tempos de coleta: Momento 1 (dia 0), 2 (dia 15), 3 (dia 30), 4 (dia 45) e 5 (dia 60). A higidez dos animais do grupo controle foi constatada através do exame físico, hemograma e exame parasitológico de fezes (Jain 1993, Ueno \& Gonçalves 1998, Pugh 2004).

A segunda parte do experimento foi conduzida em sete propriedades de criação semi-extensiva de ovinos mestiços Santa Inês. Foram selecionados ao acaso 15 ovinos em cada uma das propriedades sendo estes separados em três grupos: Animais sadios, animais com dermatite interdigital e animais com pododermatite necrosante. Foi realizada uma visita em cada propriedade, coletando-se sangue dos animais para a determinação de proteína plasmática total e proteínas de fase aguda. A higidez dos animais do grupo controle foi constatada a exemplo dos animais da primeira etapa. Seis ovinos de cada uma destas propriedades foram submetidos à coleta de material da epiderme interdigital para isolamento e identificação do agente bacteriano.

Cinco mililitros de sangue com e sem EDTA foram colhidos em tubos a vácuo, e transportados em ambiente resfriado ao laboratório. Os tubos sem anticoagulante foram mantidos em temperatura ambiente por uma hora para coagulação e o soro foi separado por centrifugação a $1500 \mathrm{G}$ por dez minutos sendo acondicionado em tubos tipo eppendorf e mantidos à temperatura de $-20^{\circ} \mathrm{C}$ até $\mathrm{o}$ momento das análises bioquímicas.

A determinação da proteína plasmática total foi realizada através de refratômetro clínico e o fibrinogênio plasmático através da técnica de precipitação pelo calor (Millar et al. 1971). As contagens total e diferencial de leucócitos foram realizadas manualmente em câmara de Neubauer e em extensões sanguíneas coradas pelo método panótico rápido, respectivamente (Jain 1993). A determinação do número de ovos por grama foi realizada pela Técnica de McMaster modificada (Gordon \& Whitlock 1939), sendo os animais com carga elevada excluídos do estudo.

A concentração da haptoglobina sérica foi avaliada com base na sua capacidade de ligação à hemoglobina. Utilizou-se uma solução padrão de haptoglobina purificada (SIGMA®) com a amplitude de $100 \mathrm{mg} / \mathrm{dL}$ a $1,5 \mathrm{mg} / \mathrm{dL}$ para elaboração da curva. As amostras de soro $(10 \mu \mathrm{L})$ foram diluídas em solução fisiológica $(90 \mu \mathrm{L})$, sendo adicionados $50 \mu \mathrm{L}$ de solução de meta-hemoglobina ovina (30mg/dL). Após incubação por dez minutos em temperatura ambiente, foram adicionados $150 \mu \mathrm{L}$ do substrato guaiacol e $50 \mu \mathrm{L}$ de peróxido de hidrogênio (Jones \& Mould 1984). Após dez minutos a leitura espectrofotométrica da absorbância foi realizada em leitor de microplacas em comprimento de onda de 495nm (Varian Cary 50 UV-Vis®). A determinação quantitativa de alfa 1 - glicoproteína ácida foi realizada em alíquotas de soro de ovinos por ensaio turbidimétrico (imunoquímico), precedida da realização de curva de calibração para validação analítica e interpolação dos dados de densidade ótica. Foi verificado que os valores obtidos na reação estavam dentro da faixa de linearidade analítica (limites de detecção propostos pelo fabricante), conforme descrito no prospecto do conjunto diagnóstico utilizado (Kovalent $®$ ). As determinações foram realizadas no Clinical Chemistry Analyzer - equipamento totalmente automatizado A-25 (Espanha, Biosystem $\AA$ ).

A coleta do material da epiderme interdigital foi realizada com auxílio de swab acondicionado em meio de transporte específico para isolamento de Dichelobacter nodosus (Thorley transport medium). Após, os frascos refrigerados foram enviados rapidamente ao laboratório HIPRA no Rio Grande do Sul para isolamento e identificação (Skerman 1989). Os dados dos dois experimentos foram analisados no programa Statistica v.7.1 (StatSoft, Inc) através de análise não paramétrica a $95 \%$ de confiança $(\mathrm{p}<0,05)$ utilizando os testes de Kruskal-Wallis e Wilcoxon com diferenças entre os grupos e momentos para ambos, respectivamente (Martins 2006).

\section{RESULTADOS}

Houve variação no número de animais acometidos pelas diferentes fases da pododermatite durante o período de dois meses de observação no primeiro experimento, com evolução não uniforme nos grupos. No momento 1 (dia 0) 51 ovinos $(72,8 \%)$ encontravam-se doentes: 20 ovinos $(28,6 \%)$ com dermatite interdigital (escore 1 ou 2) e 31 ovinos com necrose na sola, sendo que 13 animais $(18,5 \%)$ com início de necrose na sola (escore 3) e 18 animais $(25,7 \%)$ com necrose extensa (escore 4 ou 5) (Fig.2). Ao final do experimento (final das chuvas) a quantidade de doentes se resumia a 23 ovinos $(32,8 \%)$ devido a cura espontânea das lesões no restante dos animais.

Quanto à distribuição das lesões nos animais estudados,
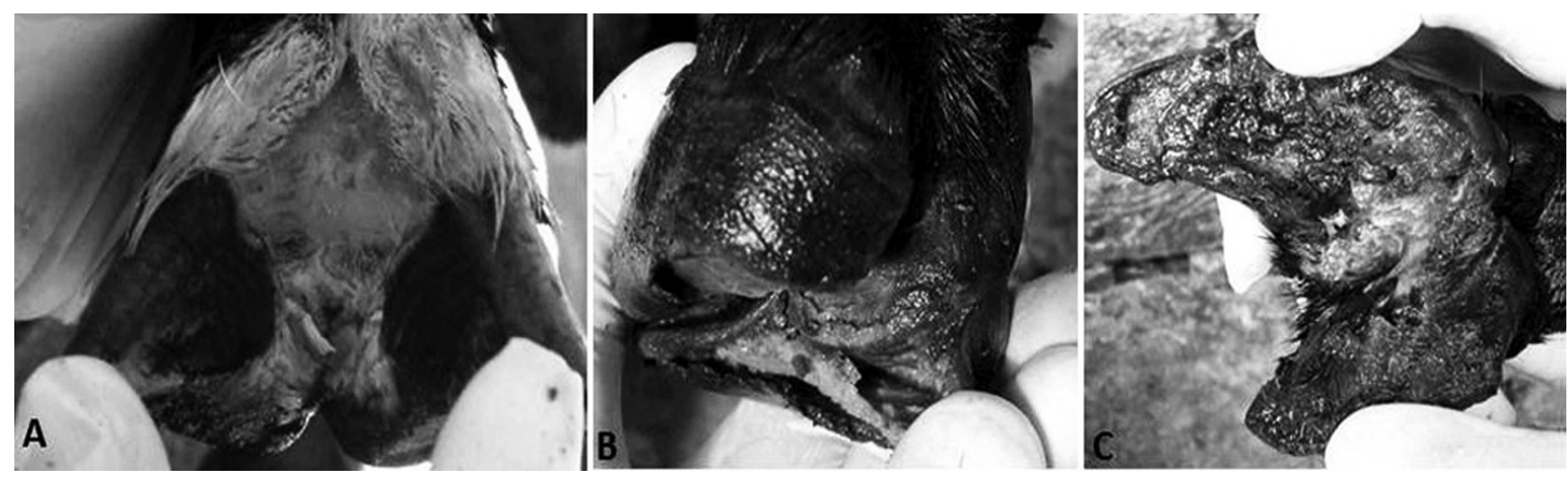

Fig.2. Fases da pododermatite infecciosa ovina. (A) Dermatite interdigital, (B) início de necrose, (C) necrose extensa. 
Quadro 1. Médias e desvio padrão de Leucócitos totais, Monócitos, Linfócitos, Eosinófilos, Neutrófilos segmentados e bastonetes absolutos $(/ \mu \mathrm{L})$; por grupos de animais Grupo-1 = Controle, Grupo-2 = Dermatite interdigital e Grupo-3 = Pododermatite necrosante, de acordo os momentos: Momento 1(Dia 0), Momento 2(Dia 15), Momento 3(Dia 30), Momento 4 (Dia 45) e Momento 5 (Dia 60)

\begin{tabular}{|c|c|c|c|c|c|c|}
\hline \multirow[t]{2}{*}{ Variáveis } & \multirow[t]{2}{*}{ Grupos } & \multicolumn{5}{|c|}{ Momentos } \\
\hline & & Momento 1 & Momento 2 & Momento 3 & Momento 4 & Momento 5 \\
\hline \multirow{3}{*}{$\begin{array}{l}\text { Leucócitos } \\
(/ \mu \mathrm{L})\end{array}$} & 1 & 983,3 & $00=$ & $\mathrm{a}$ & & \\
\hline & ( & 12037,0 & 11500,0 & 9883,33 & 9305,5 & 8941 \\
\hline & G3 & 13006,2 & $12400,00 \pm 4283,48 a$ & $10620,00 \pm 1553,43 a$ & $12607,14 \pm 3$ & 9536 \\
\hline Monócitos & G1 & 89,6 & 376,25 & $312,10 \pm$ & 347,6 & 320 , \\
\hline \multirow{2}{*}{$(/ \mu \mathrm{L})$} & G2 & 647,8 & $\mathrm{a}$ & 304,6 & 383,6 & 278 \\
\hline & G3 & 595,6 & 638,53 & $515,93=$ & 676,5 & 535, \\
\hline Linfócitos & G1 & 3137,17 & 3828,17 & 5824,80 & 4886,5 & 4378,5 \\
\hline \multirow[t]{2}{*}{$(/ \mu \mathrm{L})$} & G2 & 6 & 6,5 & 4610,33 & 4267,6 & $25,67 a$ \\
\hline & G3 & 5618, & 03,07 & 4886,13 & 3955,0 & $3628,($ \\
\hline & G1 & 08,0 & 1193,33 & 923,50 & 1182,6 & 1063,3 \\
\hline \multirow{2}{*}{$(/ \mu \mathrm{L})$} & & 4,4 & 0 , & 1192,5 & 1159,2 & 1117 \\
\hline & G & $06^{\mathrm{a}}$ & b & 1190,7 & 836,1 & 1009 \\
\hline \multirow{3}{*}{$\begin{array}{l}\text { Neutrófilos } \\
\text { segmentados } \\
(/ \mu \mathrm{L})\end{array}$} & G1 & 34,7 & 3921,2 & 2801,2 & 2304,3 & $9,80 \mathrm{a}$ \\
\hline & G2 & 91 & 7,09a & 3650,4 & $7 \mathbf{b}$ & 3628, \\
\hline & G & 5249, & 5111,3 & $3974,8 c$ & 6550,86 & $04,15 \mathrm{a}$ \\
\hline Neutr & G & 3,2 & 50 & 219,0 & 82,77 & , 47a \\
\hline & G2 & 4.7. & 5 & a & 161,67 & $12 \mathrm{a}$ \\
\hline & & & & & & \\
\hline
\end{tabular}

* As médias seguidas pela mesma letra na coluna da variável analisada não diferem entre si ao nível de 5\% de significância pelo teste de Kruskal-Wallis $(\mathrm{p}<0,05)$.

foi observado que os membros anteriores foram mais acometidos (57\%) que os membros posteriores (23\%) e que um número elevado de animais possuíam lesões nos quatro membros $(20 \%)$.

0 quadro leucocitário de cada grupo de animais do primeiro experimento foi observado em cinco momentos (Quadro 1), com diferenças significativas $(\mathrm{p}<0,05)$ entre os grupos para os diferentes tipos de leucócitos com excessão dos neutrófilos bastonetes. Para leucócitos totais e neutrófilos segmentados apenas no momento 4 é que ocorreu diferença significativa $(p<0,05)$ entre os grupos, apesar da média do grupo pododermatite necrosante ter sido superior aos demais em todos os momentos. Quanto aos linfócitos, apenas no momento 3 é que ocorreu diferença significativa $(\mathrm{p}<0,05)$ entre os grupos. Para monócitos, nos momentos 2 e 3 ocorreram diferenças significativas $(p<0,05)$ entre os grupos. Em relação aos eosinófilos, somente no momento 2 ocorreu diferença significativa $(p<0,05)$ entre os grupos, estando a média do grupo dermatite interdigital sempre acima dos valores de referência (Jain 1993).

No exame microbiológico, realizado na segunda etapa do experimento, foi isolado Dichelobacter nodosus em 26 das 42 amostras de casco enviadas, obtendo-se confirmação da presença deste agente em todas as fazendas estudadas.

Quanto a dosagem da proteína plasmática total e proteínas de fase aguda (fibrinogênio, haptoglobina e alfa-1 glicoproteína ácida) não existiram diferenças significativas $(p<0,05)$ entre os grupos para nenhuma das variáveis estudadas (Fig.3). Contudo, para haptoglobina, alguns animais dos grupos dermatite interdigital (23\%) e podermatite necrosante $(34 \%)$ apresentaram valores muitos superiores $(24,7 \mathrm{mg} / \mathrm{dL}$ até $301,8 \mathrm{mg} / \mathrm{dL}$ e $38,1 \mathrm{mg} / \mathrm{dL}$ até $149,8 \mathrm{mg} /$ $\mathrm{dL}$, respectivamente) ao intervalo de referência $(0-20 \mathrm{mg} /$ dL) citado por Skinner \& Roberts (1994).

\section{DISCUSSÃO}

A oscilação da quantidade de animais com dermatite interdigital principalmente no terceiro momento ocorreu devido à cura ou regressão espontânea da lesão, fato comum em animais com amostra benigna de Dichelobacter nodosus. Cepas responsáveis pela pododermatite benigna não apresentam fatores de virulência, desta forma ocorre regressão espontânea da doença na maioria dos animais acometidos quando o ambiente torna-se mais seco (Zhou \& Hickford 2000, Green \& George 2008). 0 próprio manejo na ocasião das visitas, com aparo e limpeza do casco dos animais com pododermatite, no intuito de melhorar a inspeção, pode ter proporcionado razoável recuperação dos mesmos e em alguns casos, principalmente em cascos com lesões iniciais leves pode ter acelerado a cura, situação também observada por Silva Sobrinho et al. (2000). A diminuição ou aumento dos fatores predisponentes também leva a declínios ou picos da expressão da doença no rebanho. Foi possível, dentro do rebanho, observar ovinos que tinham severas lesões no casco, com comprometimento da marcha, outros com claudicação perceptível apenas ao salto e alguns sem problema de claudicação, mas com infecções interdigitais ativas como observado por Abbott \& Lewis (2005).

Provavelmente o elevado índice pluviométrico (1500mm/ano) (IMA 2011) e umidade da região juntamente com os fatores relacionados às condições do solo e infra-estrutura da propriedade que permitiam a presença de áreas úmidas, acúmulo de sujidades e elevada densidade de animais no aprisco, contribuíram para o número de ovinos enfermos. Observações semelhantes foram relatadas em estudos realizados na Austrália por Abbott \& Egerton (2003), quando avaliaram rebanhos mantidos em criatórios de características climáticas diversas e por Aguiar et al. (2007) na Bahia, que concluíram que esses fatores favo- 

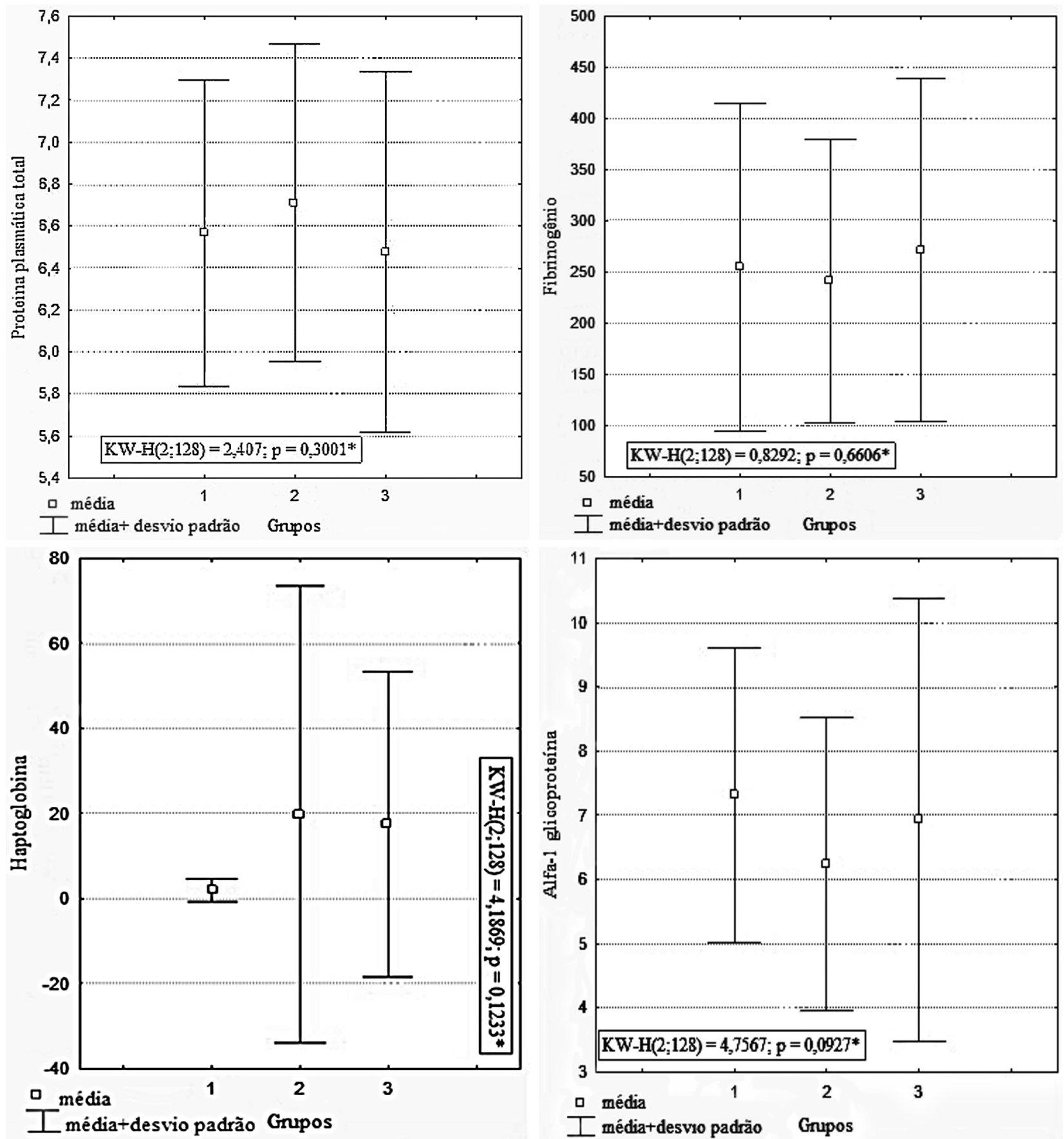

Fig.3. Médias e desvios padrões da proteína plasmática total (g/dL), fibrinogênio plasmático (mg/dL), haptoglobina(mg/dL) e alfa-1 glicoproteína ácida séricas (mg/dL) em ovinos dos grupos F1- controle, F2-dermatite interdigital e F3- pododermatite necrosante. As médias não diferem entre si ao nível de $5 \%$ de significância pelo teste de Kruskal-Wallis $(\mathrm{p}<0,05)$.

recem a persistência dos agentes no ambiente e a sua penetração no casco dos ovinos susceptíveis, desencadeando as lesões e agravando as preexistentes.

Quanto à distribuição das lesões nos animais estudados, foi observado que os membros anteriores foram mais acometidos (57\%) que os membros posteriores (23\%) similar à observação de outros autores (Pugh 2004, Wenger 2007). Porém, existem estudos que descrevem uma maior incidência de lesões nos membros posteriores (Conington et al. 2008). A presença de lesões nos membros anteriores faz com que os animais pastem ajoelhados, alteração co- mumente observada nas ovelhas utilizadas. Paul-Bokko \& Chaudhari (2001) estudando doenças podais em ovinos, notaram que o crescimento dos cascos anteriores supera os posteriores, havendo na maior parte das vezes um crescimento excessivo da muralha. Além disso, os cascos anteriores suportam cerca de $65 \%$ do peso corporal e auxiliam os posteriores na propulsão do corpo, indicando que os membros anteriores estão mais sujeitos a lesões por trauma e abalos que os posteriores. É evidente que quanto maior a demanda do exercício, mais susceptíveis ficariam os membros anteriores de apresentarem lesões (Bokko et al. 2003). 
Dentre a distribuição das lesões, observou-se também que uma grande quantidade de animais possuía lesões nos quatro membros (20\%), concordando com os dados de Aguiar et al. (2009) em levantamento realizado na Paraíba $(35,13 \%)$. Segundo Bagley (1998), Whittier \& Umberger (1996) geralmente a pododermatite acomete ambas as unhas em mais de um membro.

Quanto ao exame microbiológico a porcentagem de isolamento neste trabalho (62\%) é semelhante ao de Jimenez et al. (2003) que isolou $D$. nodosus em $64,5 \%$ das 45 amostras provenientes da região do Alentejo em Portugal, Hussain et al. (2009) com 64\% das 128 amostras na Índia; próxima aos 56,8\% obtidos por Piriz et al. (1990) em um estudo na região de Caceres na Espanha e Moore et al. (2005) com 56\% das 95 amostras de ovinos com pododermatite na Inglaterra e Pais de Gales. Por outro lado, o isolamento foi inferior ao publicado por Hurtado et al. (1998) que isolou 77,7\% em um estudo com 216 amostras de ovinos com pododermatite na Espanha.

A explicação da variação do número de amostras positivas por propriedade, é que algumas amostras podem ter um menor número de bactérias ou as lesões estarem em processo de cura (Hussain et al. 2009). 0 tipo do meio de transporte utilizado pode influenciar o isolamento por estar diretamente relacionado com a viabilidade da bactéria presente na amostra após a coleta (Nogueira et al. 2007). Cagatay \& Hickford (2005) e Belloy et al. (2007) relataram a grande dificuldade em isolar o $D$. nodosus em amostras de campo, principalmente devido ao tempo de remessa e contaminação da amostra com outras bactérias. Segundo Olson et al. (1998), em criações para confirmação do diagnóstico clínico de pododermatite infecciosa, se faz necessário o isolamento do $D$. nodosus em apenas dois ovinos acometidos no rebanho, já que os testes são caros e existem poucos laboratórios de diagnósticos veterinários regulamentados.

Quanto as variáveis leucocitárias observou-se um decréscimo gradual no número total de leucócitos do grupo dermatite interdigital desde o momento 1 até o final do experimento, porém dentro dos valores de referência para a espécie (Jain 1993). A tendência da maior parte dos animais com dermatite interdigital de regredir as lesões ou evoluir para a cura, como descrito por Zhou \& Hickford (2000) justifica o decréscimo de leucócitos observados. Além disso, a ausência de processo de necrose ou comprometimento de tecidos mais profundos neste grupo, principalmente nos animais com escore 1, leva a crer em uma menor mobilização leucocitária em relação ao grupo pododermatite necrosante.

A eosinofilia constatada é conseqüente a lesões na derme, já que segundo Feldman et al. (2000) a inflamação de superficies epiteliais ricas em mastócitos, como a pele, pode estar associada a eosinofilia e caso esta seja persistente revela uma condição de cronicidade do processo. Bignold (1995) já relatava essa relação quando avaliava o recrutamento e função dos eosinófilos.

Embora não tenha ocorrido monocitose, de acordo com Duncan et al. (2003), alterações caracterizadas por supuração, necrose e granulomas podem estar associadas a um aumento desta célula, como evidenciado no grupo pododermatite necrosante durante o experimento. Borges et al.
(2006), trabalhando com pododermatite necrosante em bovinos, também constatou elevação na contagem global de monócitos na fase final da doença.

Ao analisarmos a intensidade dos resultados do leucograma, verifica-se que estes foram de pouca magnitude (leve leucocitose (G3), em apenas um momento a neutrofilia (G3 m4) e um discreto desvio para esquerda), apesar do extenso dano e necrose tecidual existentes na última fase da doença (Duncan et al. 2003).

As médias de linfócitos do grupo dermatite interdigital e pododermatite necrosante, apesar de estarem dentro dos valores de referência para a espécie, apresentaram decréscimos no decorrer do experimento. Conforme descrito por Cole et al. (1997), existem casos em que os resultados do leucograma de ruminantes permanecem dentro das amplitudes de normalidade porém oscilações na relação neutrófilos: linfócitos (N:L) são freqüentemente observadas. Observando que os grupos dermatite interdigital e pododermatite necrosante apresentam valores de neutrófilos superiores ao grupo controle, um menor valor de linfócitos já era esperado nestes dois grupos (Quadro 1).

Quanto a dosagem de proteínas de fase aguda podemos observar que os valores das médias de haptoglobina do grupo com dermatite interdigital e pododermatite necrosante estão próximos do limite superior do intervalo de referência proposto por Skinner \& Roberts (1994), que estabeleceram um valor de $20 \mathrm{mg} / \mathrm{dL}$ como limite normal para a avaliação de possíveis alterações nos ovinos. Estes autores afirmam que as concentrações de HP maiores que $20 \mathrm{mg} / \mathrm{dL}$ indicam apenas o início ou fase intermediária da infecção e que valores superiores a $40 \mathrm{mg} / \mathrm{dL}$ indicariam uma acentuada infecção. Considerando que no grupo controle o maior valor obtido foi de $15,6 \mathrm{mg} / \mathrm{dl}$ e que no grupo dermatite interdigital existem animais com concentração de haptoglobina variando de $24,7 \mathrm{mg} / \mathrm{dL}$ até $301,8 \mathrm{mg} /$ dL (23\%) e no grupo podermatite necrosante de $38,1 \mathrm{mg} /$ $\mathrm{dL}$ até $149,8 \mathrm{mg} / \mathrm{dL}(34 \%)$ podemos inferir que provavelmente estes animais encontravam-se na fase aguda da doença. Nowroozi-Asl et al. (2008) publicaram valores de 5 a $18 \mathrm{mg} / \mathrm{dL}$ como referência para animais sadios, utilizando a raça Rabo Largo Iranianos. Outros trabalhos envolvendo a haptoglobina como marcador inflamatório em ovinos foram publicados (Regassa \& Noakes 1999, Ulutas \& Ozpinar 2006, Eckersall et al. 2007, González et al. 2007, Lepherd et al. 2009), alguns inclusive utilizando ovinos criados no Brasil que poderiam servir como parâmetro (Pereira et al. 2009, Costa et al. 2010, Bastos et al. 2011, Chaves et al. 2011), apesar de nenhum estabelecer valores de referência para as raças utilizadas. Em estudo recente, Kostro et al. (2009) estudaram ovinos antes e após transporte e abate para comparar valores de HP com estresse e lesões observadas na necropsia. Eles indicaram que animais sadios sem presença de estresse teriam valores de haptoglobina próximos ou iguais à zero, os valores se elevariam de acordo com o estresse do transporte, porém retornariam aos níveis basais após descanso. Nos animais que detinham altas concentrações de HP antes mesmo de serem transportados foi identificada, após abate, a presença de lesões em órgãos internos ou presença de lesões necróticas e purulentas nos 
cascos que, segundo os autores, seriam a causa da elevação desta proteína nestes ovinos.

Os valores de alfa-1 glicoproteína ácida dos animais sadios (controle) e dos grupos dermatite interdigital e pododermatite necrosante deste trabalho foram muito próximos e sempre abaixo de $10 \mathrm{mg} / \mathrm{dL}$. Considerando o trabalho de Eckersall et al. (2007) quanto ao papel da alfa-1 glicoproteína ácida em ovinos com linfadenite caseosa crônica, os autores também observaram que os animais sadios apresentaram valores abaixo de $10 \mathrm{mg} / \mathrm{dL}$, enquanto os doentes atingiram o nível de $38 \mathrm{mg} / \mathrm{dL}$ no pico da fase aguda (13을 dia pós-infeccão). Conhecendo-se o dia correto para mensuração, a dosagem desta proteína pode ser útil na avaliação de doenças crônicas de ovinos. Na presente pesquisa, as colheitas foram realizadas de acordo com a fase das lesões no momento das visitas, desconhecendo-se o dia exato do início da infeccção, o que deve ter interferido no resultado obtido. Contudo, Costa et al. (2010) trabalhando com infecção experimental de Staphylococcus aureus em mastite ovina concluíram ser a alfa-1 glicoproteína ácida a única proteína de fase aguda a não sofrer alterações ao longo dos momentos de observação.

No que diz respeito aos teores séricos de fibrinogênio, os mesmos apresentaram-se dentro dos valores de normalidade para a espécie ovina em todos os grupos. Isto está de acordo com os resultados de Borges et al. (2006) onde não foi observado aumento significativo do fibrinogênio em bovinos com pododermatite. Embora o fibrinogênio seja uma proteína bastante conhecida e mundialmente utilizada principalmente na clínica médica da espécie bovina, na espécie ovina ele não se mostrou um marcador sensível para a pododermatite, conforme o delineamento experimental, bem como para outras enfermidades de ovinos (Bastos et al. 2011). Isto pode estar relacionado a características de sua cinética na espécie objeto de estudo bem como também a localização do processo inflamatório circunscrito ao tecido podal.

\section{CONCLUSÃO}

Com base nos dados apresentados pelos diferentes grupos, conclui-se que as proteínas de fase aguda estudadas não se mostraram úteis como ferramentas auxiliares para o diagnóstico da pododermatite infecciosa ovina e que a resposta leucocitária foi branda, tornando difícil sua utilização para este fim. Provavelmente, um modelo de infecção que possa mensurar as fases da enfermidade, permita com mais precisão avaliar o comportamento das proteínas de fase aguda na evolução da pododermatite ovina.

Agradecimentos.- Ao Dr. Ricardo David Couto e Dr. Lázaro Silveira Santos Júnior, do Laboratório de Bioquímica Clínica da Faculdade de Farmácia da UFBA e à equipe do Laboratório de Imunologia e Biologia Molecular, ICS, UFBA, pela ajuda nas dosagens das proteínas de fase aguda estudadas.

\section{REFERÊNCIAS}

Abbott K.A. \& Egerton J.R. 2003. Effect of climatic region on the clinical expression of footrot of lesser clinical severity (intermediate footrot) in sheep. Aust. Vet. J. 81(12):756-762.

Abbott K.A. \& Lewis C.J. 2005. Current approaches to the management of ovine footrot. Vet. Journal 169:28-41.

Aguiar G.M.N , Araújo A.L., Cavalcanti A. \& Ayres M.C.C. 2007. Estabeleci- mento de escore para avaliação clínica de lesões podais e sua ocorrência em ovinos criados na microrregião dos tabuleiros costeiros no estado da Bahia. Anais III Simpósio Internacional sobre Caprinos e Ovinos de Corte, João Pessoa, PB. (CD-ROM)

Aguiar G.M.N., Assis A.C.O., Silva T.R., Araújo J.R.B., Garino Junior F., Simões S.V. \& Riet-Correa F. 2009. Pododermatite infecciosa em ovinos e caprinos no sertão paraibano. Ciênc. Anim. Bras. 1:585-590.

Bagley C.V. 1998. Contagious foot rot: An update. Utah State University Extension Animal Health Fact Sheet. n.7, November.

Bastos B.L., Meyer R., Guimarães J.E., Ayres M.C., Guedes M.T., Moura-Costa L.F., Burghgrave U.S., Sena L., Azevedo V. \& Portela R.W. 2011. Haptoglobin and fibrinogen concentrations and leukocyte counts in the clinical investigation of caseous lymphadenitis in sheep. Vet. Clin. Pathol. 40:496-503.

Belloy L., Giacometti M., Boujon P. \& Waldvogel A. 2007. Detection of Dichelobacter nodosus in wild ungulates (Capra ibex ibex and Ovis aries musimon) and domestic sheep suffering from foot rot using a two-step polymerase chain reaction. J. Wildl. Dis. 43(1):82-88.

Bendigo T.G. 2007. Footrot in sheep: diseases facts, diagnosis, treatment, prevention and damage control, benign footrot. Agriculture Notes. State of Victoria, Departament of Primary Industries USA.

Bignold L.P. 1995. The eosinophil leukocyte: controversies of recruitment and function. Cell. Mol. Life Sci. 51(4):317-326.

Bokko B.P., Adamu S.S. \& Mohammed A. 2003. Limb conditions that predispose sheep to lameness in the arid zone of Nigeria. Small Rumin. Res. 47(2):165-169.

Bonino J., Casaretto A., Mederos A., Ferreira G. \& Gil A. 2000. Relevamiento epidemiológico de la prevalencia de Footrot en ovinos del Uruguay. Producción Ovina 13:9-25.

Borges N.C., Vieira D., Silva L.A.F. \& Fioravanti M.C.S. 2006. Valores leucocitários e nível de fibrinogênio plasmático de bovinos com pododermatite. Ciênc. Anim. Bras. 7(1):97-102.

Cagatay I.T. \& Hickford J.G.H. 2005. Update on ovine footrot in New Zealand: Isolation, identification, and characterization of Dichelobacter nodosus trains. Vet. Microbiol. 111(3/4):171-180.

Chaves D., Fagliari J. \& Silva P. 2011. Proteinograma sérico de ovinos intoxicados experimentalmente por salsa. Ciênc. Anim. Bras. 12(3):547-553.

Cole D.J., Roussel A.J. \& Whitney M.S. 1997. Interpreting a bovine CBC: Evaluating the leukon and acute-phase proteins. Vet. Med. 92:470.

Conington J., Hosie B., Nieuwhof G.J., Bishop S.C. \& Bünger L. 2008. Breeding for resistance to footrot--the use of hoof lesion scoring to quantify footrot in sheep. Vet. Res. Commun. 32(8):583-589.

Costa N.A., Simões L.C.V., Santos R.A., Afonso J.A.B., Fagiliari J.J., Cardoso E.C., Soares P.C. \& Mendonça C.L. 2010. Proteinograma e teores de cobre, ferro e zinco no soro sanguíneo de ovelhas da raça Santa Inês com mastite experimental por Staphylococcus aureus. Pesq. Vet. Bras. 30(5):435-442.

Duncan J.R., Prasse K.W. \& Mahaffey E. 2003. Veterinary Laboratory Medicine. $4^{\text {th }}$ ed. Ames, Iowa. $450 \mathrm{p}$.

Eckersall P.D., Lawson F.P., Bence L., Waterston M.M., Lang T.L., Donachie W. \& Fontaine M.C. 2007. Acute phase protein response in an experimental model of ovine caseous lymphadenitis. BMC Vet. Res. 35:1-6.

Feldman B.F., Zinkl J.G. \& Jain C.N. 2000. Schalm's Veterinary Hematology. $5^{\text {th }}$ ed. Lippincott Williams and Wilkins, Philadelphia. 1344p.

González F.H.D., Martínez-Subiela S. \& Cerón J.J. 2007. Haptoglobina en rumiantes: generalidades y posibles aplicaciones clínicas. Anales de Veterinaria Murcia 23:5-17.

Gordon H.M. \& Whitlock H.V. 1939. A new technique for counting nematode eggs in sheep faeces. J. Council Scient; Industr; Res., Australia, 12:50-52.

Green L.E. \& George T.R.N. 2008. Assement of current knowledge of footrot in sheep with particular reference to Dichelobacter nodosus and implications for elimination or controle strategies for sheep in Great Britain. Vet. Journal 175:173-180.

Hurtado M.A., Píriz S., Valle J., Jimenez R. \& Vadillo S. 1998. Aetiology of ovine footrot in Spain. Vet. Rec. 142(3):60-63. 
Hussain I., Wani S.A., Qureshi S.D. \& Farooq S. 2009. Serological diversity and virulence determination of Dichelobacter nodosus from footrot in India. Molecular and Cellular Probes 23(2):112-114

IMA 2011. Secretaria do Meio Ambiente. Isoietas Bahia 2008. Disponível em <http://www.cra.ba.gov.br/index.php/geobahia/arquivos/doc_download/24-distribuicao-dos-indices-pluviometricos-isoietas-ba-2008> Acesso 12 nov. 2011.

Jain N.C. 1993. Essential of Veterinary Hematology. Lea and Febiger, Philadelphia. $417 \mathrm{p}$

Jelinek P.D., Depiazzi D.A., Galvin D.A., Spicer I.T., Palmer M.A. \& Pitman D.R. 2000. Ocurrence of different strains of Dichelobacter nodosus in new clinical lesions in sheep exposed to footrot associated with multi-strains infections. Aust. Vet. J. 78(4):273-276.

Jimenez R., Piriz S., Martin-Palomino P., Mateos E. \& Vadillo S. 2003. Aetiology of ovine footrot in the Portuguese region of Alto Alentejo. J. Vet. Med. 50:118-120.

Jones G.E. \& Mould D.L. 1984. Adaptation of the guaiacol (peroxidase) test for haptoglobulins to a microtitration plate system. Res. Vet. Sci. 37:8792

Kostro K., Jarosz L., Gruszecki T., Junkuszew A. \& Lipecka C. 2009. Utility of haptoglobin assay for sheep welfare and health status evaluation in preand postslaughter period. Bull. Vet. Inst. Pulawy 53:111-116.

Lepherd M.L., Canfield P.J., Hunt G.B. \& Bosward K.L. 2009. Haematological, biochemical and selected acute phase protein reference intervals for weaned female Merino lambs. Aust. Vet. J. 87(1/2):5-11.

Martins G.A. 2006. Estatística Geral e Aplicada. 3a ed. Atlas, São Paulo. 421p.

Millar H.R., Simpson J.G. \& Stalker A.L. 1971. An evolutation of the heat precipitation method for plasma fibrinogen estimation. J. Clin. Pathol. 24:827-830.

Moore L.J., Wassink G.J., Green L.E. \& Grogono-Thomas R. 2005. The detection and characterisation of Dichelobacter nodosus from cases of ovine footrot in England and Wales. Vet. Microbiol. 108:57-67.

Morcombe P. 2008. Benign footrot in sheep and goats. Western Australian Agricultural Authority Farmnote n.330.

Murata H., Shimada N. \& Yoshioka M. 2004. Current research on acute phase proteins in veterinary diagnosis: An overview. Vet. Journal. 168(1):28-40.

Nogueira D.C., Ueda S.M., Murça M.A., Hida W.T., Felberg S., Serruya L. \& Hida R.Y. 2007. Comparação entre dois meios de coleta e transporte para o estudo da microbiota conjuntival de indivíduos normais. Arq. Bras. Oftalmol. 70:929-934.

Nowroozi-Asl A., Nazifi S. \& Bahari A. 2008. Determination of serum haptoglobin reference value in clinically healthy Iranian fat-tailed sheep. Iranian J. Vet. Res. 9(2)23:171-173.

Olson M.E., Gard M.S., Gradin J. \& Morck D.W. 1998. Serological classifica- tion and virulence determination of Dichelobacter nodosus isolated from Alberta and British Columbia sheep. Can. J. Vet. Res. 62(1):33-37.

Paul-Bokko B. \& Chaudhari S.U.R. 2001. Prevalence of lameness in sheep in the northeastern region of Nigeria. Int. J. Agric. Biol. 3(4):519-521.

Pereira W., Faria J., Silva P., Hatayde M. \& Fagliari J. 2009. Proteinograma sérico de ovinos intoxicados por cobre. Ciênc. Anim. Bras. 1:354-359.

Pfeffer A., Rogers K.M., O'Keeffe L. \& Osborn P.J. 1993. Acute phase protein response, food intake, liveweight and lesions following intratoracic injection of yeast in sheep. Res. Vet. Sci. 55:360-366.

Piriz S., Cuenca R., Valle J. \& Vadillo S. 1990. Isolation and identification of anaerobic bacteria from ovine foot rot in Spain. Res. Vet. Sci. 49(2):245247.

Pugh D.G. 2004. Clínica de Ovinos e Caprinos. Roca, São Paulo. 513p.

Regassa F. \& Noakes D.E. 1999. Acute phase protein response of ewes and the release of PGFM in relation to uterine involution and the presence of intrauterine bacteria. Vet. Rec. 144:502-506.

Rodrigues C.A., Mendes L.C.N., Peiró J.R. \& Feitosa F.L.F. 2001. Ocorrência de um surto de "footrot" em rebanho de ovinos na região de Araçatuba, SP, Brasil. Revta Educ. Contin. CRMV-SP 4(3):12-19.

Silva Sobrinho A.G., Tonhasca J.G., Nogueira-Couto R.H., Resende K.T. \& Kronka S.N. 2000. Utilização da própolis no tratamento curativo da pododermite necrótica em ovinos. Revta Mensagem Doce n.56.

Skerman T.M. 1989. Isolation and identification of Bacteroides nodosus, p.85-102. In: Egerton J.R., Yong W.K. \& Riffkin G.G. (Eds), Footrot and Foot Abscess of Ruminants. CRC Press, Florida.

Skinner J.G. \& Roberts L. 1994. Haptoglobin as an indicator of infection in sheep. Vet. Rec. 134:33-36.

Tadich N. \& Hernandez M. 2000. Prevalencia de lesiones podales en ovinos de 25 exploraciones familiares de la provincia de Valdivia, Chile. Archs Med. Vet. 32(1):63-74.

Ueno H. \& Gonçalves P.C. 1998. Manual para diagnóstico das helmintoses de ruminantes. $4^{\mathrm{a}}$ ed. Japan International Cooperation Agency. 143p.

Ulutas P.A. \& Ozpinar A. 2006. Effect of Mannheimia (Pasteurella) haemolytica infection on acute-phase proteins and some mineral levels in colostrum-breast milk-fed or colostrum-breast milk-deprived sheep. Vet. Res. Commun. 30:485-495.

Wenger I. 2007. Winning the war on sheep footrot. Sheep Canada Magazine, Summer, p.5-9.

Whittier W.D. \& Umberger S.H. 2009. Control, treatment and elimination of foot rot from sheep. Virginia Cooperative Extension n.410-028, May.

Zhou H. \& Hickford J.G.H. 2000. Extensive diversity in New Zealand Dichelobacter nodosus strains from infected sheep and goats. Vet. Microbiol. 71:113-123. 